\title{
Genetic relationships within the genus Beta determined using both PCR-based marker and DNA sequencing techniques
}

\author{
YULONG SHEN, BRIAN V. FORD-LLOYD \& H. J OHN NEWBURY* \\ School of Biological Sciences, University of Birmingham, Edgbaston, Birmingham B15 2TT, UK
}

\begin{abstract}
The sequences of ITS1 of the internal transcribed spacer regions of nuclear ribosomal DNA from 11 species or subspecies in four sections of the genus Beta were compared. Phylogeny of these wild beet taxa was inferred from the sequence data using phenetic and phylogenetic analyses. Multiple accessions from the same 11 taxa were subjected to random amplified polymorphic DNA (RAPD) analysis, and the data were analysed phenetically. With both molecular techniques and each analysis, three distinctive groups were formed: species from section Beta formed one group; species from section Procumbentes formed a very distinct group; and species from both section Nanae and section Corollinae clustered together forming the third group, which is closer to Beta than to Procumbentes. The RAPD data revealed withinsection interspecies relationships that are consistent with those reported previously; this was not always the case using the single-locus sequence data.
\end{abstract}

Keywords: Beta, internal transcribed spacer (ITS), phylogeny, rDNA, RAPD, wild beets.

\section{Introduction}

The genus Beta is divided into four sections: Beta, Corollinae, Nanae and Procumbentes. Section Beta includes the crop species $B$. vulgaris which contains sugar beet, fodder beet and chards. The systematics within this economically important genus have been subject to disagreement (Kishima et al., 1987; Santoni \& Berville, 1992), but molecular data may provide a solution to the taxonomic problems, as well as information about the possible evolutionary relationships of sections and species within the genus. DNA sequence data are increasingly providing valuable information for evolutionary studies (Olmstead \& Palmer, 1994) and, in plants, chloroplast genes and the $18 \mathrm{~S}-5.8 \mathrm{~S}-25 \mathrm{~S}$ ribosomal DNA have been the main sequences used for such studies. The $18 \mathrm{~S}-5.8 \mathrm{~S}-25 \mathrm{~S}$ rDNA is attractive for phylogeny reconstruction because of high copy number, universality and diverse rate of evolution within and among component subunits and spacers (Baldwin, 1994). Although the regions of rDNA that encode the mature rRNAs are useful for deep phylogeny inference within angiosperms as a whole, the two internal transcribed spacers (ITS1 and ITS2; Fig. 1) of nuclear rDNA have evolved more rapidly than

*Correspondence. E-mail: h.j.newbury@bham.ac.uk the coding regions that flank them and are suitable for comparison of closely related taxa. For example, phylogenetic analysis of ITS sequences from several genera in the subtribe Masinae of the Compositae (Baldwin, 1992) has yielded results highly concordant with the phylogeny of species based on chloroplast DNA restriction site mutations. The ITS sequences have also revealed phylogeny in the genus Calycadenia which has close agreement with that based on the interpretation of cytological and morphological data (Baldwin, 1992). In sugar beet, the $18 \mathrm{~S}-5.8 \mathrm{~S}-25 \mathrm{~S}$ rDNA repeats have been mapped onto chromosomes using fluorescent in situ hybridization (Schmidt et al., 1994). Restriction fragment length polymorphism (RFLP) analysis of Beta species has been carried out using rDNA probes, and variation in restriction sites was detected within the nontranscribed intergenic spacer (IGS) region but not in the transcribed ITS region (Santoni \& Berville, 1992).

As a contrasting technique, RAPD (Williams et al., 1990) has been widely used to reveal genetic variation in crops. The technique has been used successfully for revealing polymorphism within species (Demeke \& Adams, 1994). For the study of genetic relationships above the species level, the use of RAPD has been criticized for revealing unreliable phylogenies because of possible lack of homology of 
Fig. 1 Diagram of the organization of the ITS region of the $18 \mathrm{~S}-5.8 \mathrm{~S}-25 \mathrm{~S}$ nuclear rDNA repeat. Arrows indicate approximate positions of primers for sequencing. Primer names follow White et al. (1990). The nontranscribed intergenic spacer (IGS) between $25 \mathrm{~S}$ and $18 \mathrm{~S}$ is not shown.

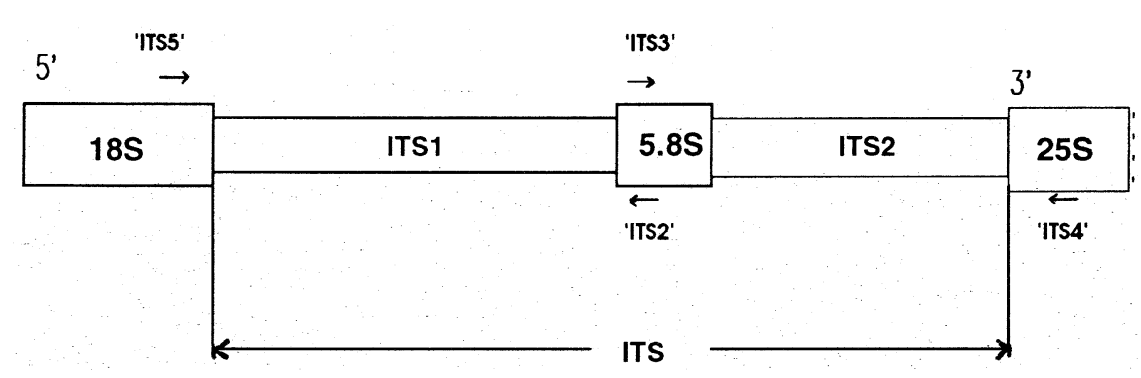

co-migrating bands (Brummer et al., 1995). However, several studies have used RAPD successfully to reveal relationships at the section level or above in several genera, including Oryza (Martin et al., 1997), Medicago (Brummer et al., 1995) and Rosa (Millan et al., 1996); in each case, the RAPDderived phylogenies have been found to be in good agreement with those produced using other methods. In beets, RAPD analysis has so far been used in the taxonomic characterization of species/ subspecies of wild annual beets within the section Beta (Shen et al., 1996) and five species within section Corollinae (Reamon-Buttner et al., 1996).

Here, we present results using ITS1 sequence data to illustrate the phylogenetic relationships of species in the genus Beta. We also show that similar genetic relationships are revealed using RAPD when species from each of the sections of the genus are analysed, confirming the reliability of RAPD for studying variation between species and sections of a genus.

\section{Materials and methods}

\section{ITS (ITS1-5.8S-ITS2) amplification and sequencing}

Thirteen accessions from the University of Birmingham Beet Germplasm Collection, representing members of all four sections, were used for ITS1 sequencing (Table 1). In addition, the ITS1 region of Chenopodium album was sequenced to provide an outgroup for the phylogenetic analysis. Leaf tissues from greenhouse-grown beet plants and a $C$. album plant growing naturally were used for DNA extraction according to the method of Sabir et al. (1992). Between two and 10 plants were sampled for each accession used in DNA sequencing. The yield of DNA was estimated by electrophoresis on an agarose gel $(0.7 \%)$ along with $\lambda$ phage DNA standards. PCRs were performed in $25 \mu \mathrm{L}$ volumes containing $1.0 \mathrm{ng}$ of genomic DNA, $200 \mu \mathrm{m}$ of each dATP, dCTP, dGTP and dTTP, $2 \mu \mathrm{M}$ of each primer, $1.0 \mathrm{U}$ of $\mathrm{Taq}$ polymerase, $1 \times$ ammonium incubation buffer and $2.5 \mathrm{~mm}$ magnesium chloride.
The primers were ITS5 (5'-GGAAGTAAAAGTCGTAACAAGG-3') and ITS4 (5'-TCCTCCGCTATATGATATGC-3') (White et al., 1990; Fig. 1). Amplifications were performed in a thermocycler (Hybaid-Omnigene) programmed as follows: one cycle at $95^{\circ} \mathrm{C}$ for $2 \mathrm{~min}$; two cycles of $30 \mathrm{~s}$ at $95^{\circ} \mathrm{C}, 1 \mathrm{~min}$ at $57^{\circ} \mathrm{C}$ and $2 \mathrm{~min}$ at $72^{\circ} \mathrm{C}$; two cycles of $30 \mathrm{~s}$ at $95^{\circ} \mathrm{C}, 1 \mathrm{~min}$ at $55^{\circ} \mathrm{C}$ and $2 \mathrm{~min}$ at $72^{\circ} \mathrm{C} ; 31$ cycles of $30 \mathrm{~s}$ at $94^{\circ} \mathrm{C}, 1 \mathrm{~min}$ at $55^{\circ} \mathrm{C}$ and $2 \mathrm{~min}$ at $72^{\circ} \mathrm{C}$; and finally $72^{\circ} \mathrm{C}$ for $5 \mathrm{~min}$. In order to separate the amplified product from the residual primers, 10-12 reaction mixtures from one accession were pooled and subjected to electrophoresis in a $1.2 \%$ (w/v) low-melting-point agarose gel using TAE buffer (Sambrook et al., 1989). The desired DNA fragment was cut out of the gel and recovered using a Geneclean II Kit (Bio 101, Vista, CA, USA) according to the manufacturer's instructions. The DNA was used for sequencing using an Applied Biosystem 373A Automatic DNA Sequencer. Only the ITS1 region (White et al., 1990; Fig. 1) was sequenced, using ITS5 as a forward primer and ITS2 (ITS2: 5'-GCTGCGTTCTTCATCGATGC-3'; White et al., 1990; Fig. 1) as reverse.

\section{Alignment of ITS1 sequences and phylogenetic reconstruction}

The sequences of ITS1 obtained using the two different primers (ITS5 and ITS2) for each of the 13 samples of beet plus C. album were compared and checked. The sequences were aligned by eye using the LINE-UP program of the GCG sequence analysis software package (GCG, 1995). Divergence between ITS1 sequences in pairwise comparisons was calculated using the Kimura two-parameter method (Swofford \& Olsen, 1990). In this method, different rates of transversions and transitions are taken into account and the gaps are not scored. The calculation was carried out using the DISTANCES program in the GCG software package (GCG, 1995). Phylogenetic trees were generated using the distances with the 
GROWTREE program and using both UPGMA and neighbour-joining options.

\section{RAPD analysis}

DNA was extracted from 25 accessions representing all the taxa in the Birmingham Beta collection (Table 1) as described above. PCR amplification and electrophoresis were carried out in duplicate following the method used for rice (Virk et al., 1995). The primers used were OPG-12, OPH-16, OPK-10, OPM-17 and OPM-18 (Operon Technology). Except for accessions from section Beta, in which DNA samples used for amplification were pooled, all the other DNA samples were from single plants. The DNA amplification reactions were performed in a volume of $25 \mu \mathrm{L}$ containing approximately $1 \mathrm{ng}$ of genomic DNA, $200 \mu \mathrm{M}$ of each dATP, dCPT, dGTP and dTTP, $0.4 \mu \mathrm{M}$ primer, $1.0 \mathrm{U}$ of Taq polymerase, $1 \times$ ammonium incubation buffer and $2.5 \mathrm{~mm}$ magnesium chloride. The amplification was performed in a thermocycler (Hybaid-Omnigene) programmed as follows: one cycle of $95^{\circ} \mathrm{C}$ for $2 \mathrm{~min}$; two cycles of $30 \mathrm{~s}$ at $95^{\circ} \mathrm{C}, 1 \mathrm{~min}$ at $37^{\circ} \mathrm{C}$ and $2 \mathrm{~min}$ at $72^{\circ} \mathrm{C}$; two cycles of $30 \mathrm{~s}$ at $95^{\circ} \mathrm{C}, 1 \mathrm{~min}$ at $36^{\circ} \mathrm{C}$ and $2 \mathrm{~min}$ at $72^{\circ} \mathrm{C} ; 41$ cycles of $30 \mathrm{~s}$ at $94^{\circ} \mathrm{C}, 1 \mathrm{~min}$ at $36^{\circ} \mathrm{C}$ and $2 \mathrm{~min}$ at $72^{\circ} \mathrm{C}$; and finally $72^{\circ} \mathrm{C}$ for $5 \mathrm{~min}$. Aliquots of $16 \mu \mathrm{L}$ of amplified products were loaded onto $1.4 \%(\mathrm{w} / \mathrm{v})$ agarose gels for electrophoresis in $0.5 \times \mathrm{TBE}$ buffer and run at $200 \mathrm{~V}$ for about $2 \mathrm{~h}$. Gels were stained with ethidium bromide and photographed under UV light using the IS-500 Digital Imaging System (Alpha Innotech Corporation). Only strong bands that were observed in both duplicate

Table 1 Beta material used

\begin{tabular}{|c|c|c|c|c|c|}
\hline Accession & Species/subspecies & Abbreviation & Section & $\begin{array}{l}\text { No. of plants } \\
\text { used for RAPD }\end{array}$ & $\begin{array}{c}\text { Country of } \\
\text { origin }\end{array}$ \\
\hline NA & Chenopodium album & $\mathrm{ALB} \dagger$ & NA & 1 & UK \\
\hline B0205 & lomatogona & LOM & Corollinae & 2 & Turkey \\
\hline B0213 & lomatogona & $\mathrm{LOM} \dagger$ & Corollinae & 2 & Turkey \\
\hline B0234 & lomatogona & LOM & Corollinae & 3 & Turkey \\
\hline B0224 & trigyna & TRI & Corollinae & 1 & Turkey \\
\hline B0349 & trigyna & TRI & Corollinae & 1 & \\
\hline B0367 & trigyna & TRI† & Corollinae & 2 & \\
\hline B0368 & corolliflora & COR & Corollinae & 2 & \\
\hline B0403 & corolliflora & COR & Corollinae & 2 & Armenia \\
\hline B0537 & corolliflora & $\mathrm{COR} \dagger$ & Corollinae & 2 & \\
\hline B0424 & adanensis & ADA & Beta & $10 \ddagger$ & Greece \\
\hline B0423 & adanensis & $\mathrm{ADA} \dagger$ & Beta & 1 & Greece \\
\hline B0588 & macrocarpa & $\mathrm{MCC} \dagger$ & Beta & $4 \ddagger$ & Canary Is. \\
\hline B0051 & vulgaris spinach beet & VU1† & Beta & 1 & \\
\hline B0079 & vulgaris sugar beet & VU2† & Beta & 1 & \\
\hline B0534 & patellaris & PAT & Procumbentes & 1 & Canary Is. \\
\hline B0555 & patellaris & PAT & Procumbentes & 2 & Canary Is. \\
\hline B1108 & patellaris & PAT & Procumbentes & 3 & \\
\hline B0576 & procumbens & $\mathrm{PRO}(\mathrm{PR} 1) \dagger$ & Procumbentes & 5 & Canary Is. \\
\hline B0535 & procumbens & $\mathrm{PRO}(\mathrm{PR} 2) \dagger$ & Procumbentes & 3 & Canary Is. \\
\hline B0536 & webbiana & WEB & Procumbentes & 3 & \\
\hline B0566 & webbiana & $\mathrm{WEB} \dagger$ & Procumbentes & 3 & Canary Is. \\
\hline
\end{tabular}

*Where information available.

$\dagger$ Accessions used for RAPD and sequencing.

$\ddagger$ Accessions for which pooled samples were used. 
amplifications were scored. RAPD bands showing variation across the 48 samples were used as polymorphic markers and were scored as present (1) or absent (0) for each accession. The data were then subjected to analysis using Jaccard's similarity coefficient, and a dendrogram was generated using UPGMA cluster analysis (NTSYS-pc: Rohlf, 1992).

\section{Results}

ITS fragments were efficiently amplified for all the 13 beet accessions and $C$. album. A band of the expected size (740 bp) was obtained, although some accessions also yielded a faint band of about $480 \mathrm{bp}$, probably because of weak, non-specific primer binding within the ITS region during PCR. The sequences of ITS1 fragments were aligned and, by comparison of the sequence data with published sequences in other crops (Yokota et al., 1989), the boundaries of ITS1 were determined. Because of insertions or deletions, four gaps of between one and four bases were included in the alignment (Fig. 2). Species in section Procumbentes have 238-239 bp sequences, in section Beta $241 \mathrm{bp}$ and in sections Nanae and Corollinae 243-244 base sequences, whereas ITS1 in C. album is $221 \mathrm{bp}$ long. Omitting base insertions and deletions leaves 211 bases, of which $86(41 \%)$ are variable across the 14 sequences.

Pairwise comparisons of transitions and transversions of the ITS1 regions and the Kimura two-parameter distances were calculated. The distances among pairwise comparisons ranged from 0 to 48.85 . The distances between species within sections were usually less $(0-2.53)$ than those between sections, except for those between species in sections Nanae and Corollinae.

The phylogenetic relationships among species were the same in the trees generated using the distance data and both UPGMA and neighbourjoining methods. To illustrate the distances between accessions, a phylogenetic tree was drawn using the data from the neighbour-joining analysis (Fig. 3). Three groups were formed: species from section Procumbentes formed a distinct group, species from section Beta formed another and species from sections Nanae and section Corollinae formed the third group (closer to Beta than to Procumbentes). In section Beta, two accessions from B. vulgaris and one accession from $B$. maritima did not show any variation in the ITS1 region and grouped as one. Beta macrocarpa is more distantly related to $B$. vulgaris than is $B$. adanensis. In section Procumbentes, two accessions from $B$. procumbens were separated; one of them had the same sequence as B. webbiana and the other differed by six bases. In section Corollinae, B. macrorhiza and B. trigyna did not show sequence variation in the ITS1 region and clustered together. Beta nana, the single species in section Nanae, was grouped with species from section Corollinae; $B$. nana was closer to $B$. trigyna and $B$. macrorhiza than to $B$. corolliflora or B. lomatogona.

Forty-eight DNA samples derived from 25 accessions were analysed using RAPD (see Table 1). The primers used were selections of those that had been used in a previous study (Shen et al., 1996), and all five primers produced reliable and reproducible banding patterns. Accessions from the four sections gave rise to characteristic RAPD profiles, which were so obviously different as to allow identification at the section level by eye. An example of the profiles is shown in Fig. 4. For numerical analysis, 31 polymorphic bands were scored, and the data were analysed using the simple matching coefficient and UPGMA clustering (NTSYs-pc: Rohlf, 1992) to produce a dendrogram (Fig. 5). All accessions from section Procumbentes formed one group (A) well separated from the others. Within this group, plants from each accession were generally clustered together. However, accessions putatively belonging to the same species were not always grouped together. The remainder of the accessions formed another main group consisting of three subgroups: accessions from section Beta formed one group (B), although the four accessions (B0317, B0424, B0588 and B0731) were well separated; accessions from section Nanae showed no polymorphism and formed a tight group (C), which is closer to section Corollinae than section Beta. Within section Corollinae (Fig. 5), accessions from $B$. lomatogona clustered together and formed a distinctive group (E). Accessions from the other three species grouped together (D) but, although plants from the same accessions did cluster together, the subgrouping did not correlate well with the putative species identification.

\section{Discussion}

ITS1 base sequence and RAPD banding data have been obtained for 11 species or subspecies of Beta and for Chenopodium album. Both the phylogeny obtained using the ITS1 sequence data and the genetic relationships revealed using RAPD are in general agreement with the relationships defined using other methods; these include relationships revealed from taxonomically more restricted analyses of RFLP studies of chloroplast (Kishima et al., 1987, 1995), mitochondrial (Senda et al., 1995) 
1

NAN TCGAAACCTG CAAAGCAGA. GCAACCAGCG AACATGTTTT ACATCCGTGG

TRI TCGAAACCTG CAAAGCAGA. GCAACCAGCG AACATGTTTT ACATCCGTGG

LOM TCGAAACCTG CAAAGCAGA. GCAACCAGCG AACATGTTTT ACATCCGTGG

COR TCGAAACCTG CAAAGCAGA. GCAACCAGCG AACATGTTTA ACATCCGTGG

MCR TCGAAACCTG CAAAGCAGA. GCAACCAGCG AACATGTTTT ACATCCGTGG

WEB TCGAAACCTG CAAAGCAGA. GCAACCAGCG AACTTGTTTA TTACCCGTGG

RP2 TCGAAACCTG CAAAGCAGA. GCAACCAGCG AACTTGTTTA TTACCCGTGG

PR1 TCGAAACCTG CAAAGCAGA. GCAACCAGCG AACTTGTTTA TTACCCGTGG

vU1 TCGAATC.TG CAAAGCAGA. GCAACCAGCG AACATGTTTT ACATCTGTGG

VU2 TCGAATC.TG CAAAGCAGA. GCAACCAGCG AACATGTTTT ACATCTGTGG

ADA TCGAATC.TG CAAAGCAGA. GCAACCAGCG AACATGTTTT ACATCTGTGG

MCC TCGAATC.TG CAAAGCAGA. GCAACCAGCG AACATGTTTT ACATCTGTGG

MAR TCGAATC.TG CAAAGCAGA. GCAACCAGCG AACATGTTTT ACATCTGTGG

ALB TCGAAACCTG CCCAGCAGAA GCGACCAGAG AACATGTTTA TCAT......

CONSENSUS TCGAAaCCTG CaaAGCAGA. GCaACCAGCG AACaTGTTTt acAtccgtgg

51

NAN GACGGGGGTG TTGGTATGAT GCTTTAGCTT GTGCCAGCCC CTCCCCC.CA

TRI GACGGGGGTG TTGGTATGAT GCTTCAGCTT GTGCCAGCCC CTCCCCC.CA

LOM GACGGGGGTG TTGGTACGAT GCTTTAGCTT GTGCCAGCCC CTCCCCC.CA

COR GACGGGGGTG TTGGTATGAT GCTTTAGCTT GTGCCAGCCC CTCCCCC.CA

MCR GACGGGGGTG TTGGTATGAT GCTTCAGCTT GTGCCAGCCC CTCCCCC.CA

WEB GATAGGAGTG CTTGCATGCA CCTTTGGTTC ATGCAAGTCC TTATCCTGCA

RP2 GATAGGAGTG CTTGCATGCA CCTTTGGTTC ATGCAAGTCC TTATCCTGCA

PR1 GATGGGAGTG CTTGCATGCA CCTGTGGTTC ATGCAAGCCC TTATCCTGCA

VU1 GAAGGGGGTG CTGGCACGAT GCTTTGGGTT GTGCCAGCCC CTCCCC..CA

VU2 GAAGGGGGTG CTGGCACGAT GCTTTGGGTT GTGCCAGCCC CTCCCC.. CA

ADA GAAGGGGGTG CTGGGACGAT GCTTTGGGTT GTGCCAGCCC CTCCCC.. CA

MCC GACGGGGGTG TTGGCACGAT TCTTTAGGTT GTGCCAGCCC CTCCCC..CA

MAR GAAGGGGGTG CTGGCACGAT GCTTTGGGTT GTGCCAGCCC CTCCCC..CA

ALB GAACGGGGTC GGGGTGAAAG CCCCTTCCTC AAGCCGGGGA ATCGCTCCGC

CONSENSUS GACgGGgGTg ctgGcatgat gCtttggcTt gtGCcaGcCC cTCCCC..ca 101

150

NAN TGTCGCGGGG CACTCCTACT TGG.TGTGCT CCCCGGC.GA AAAAAACAAA

TRI TGTCGCGGGG CACTCCTACT TGG.TGTGCT CCCCGGC.GA AAAAAACAAA

LOM TGTCGCGGGG CACTCCTACT TGG.TGTGCT CCCCGGCAAA AAAAAACAAA

COR TGTCGCGGGG CACTCCTACT TGG. TGTGCT CCCCGGC.GA AAAAAACAAA

MCR TGTCGCGGGG CACTCCTACT TGG.TGTGCT CCCCGGC.GA AAAAAACAAA

WEB T..CGAGGGG CTCTCCTCTA TGGGAGTGCT TCTCGGC... AAATAACAAA

RP2 T. .CGAGGGG CTCTCCTCTA TGGGAGTGCT TCTCGGC... A. AAATAACAAA

PR1 T...CGAGGGG CTCTCCTCTT TGGGAGTGCT TCTCGGC... AAATAACAAA

vU1 TGTCGCGGGG CACTCCTACT TGG. TGTGCT CCCCGGC.GA AAAAAACAAA

vU2 TGTCGCGGGG CACTCCTACT TGG.TGTGCT CCCCGGC.GA AAAAAACAAA

ADA TGTCGCGGG CACTCCTACT TGG.TGTGCT CCCCGGC.GA AAAAAACAAA

MCC TGTCGCGGGG CACTCCTACT TGG.TGTGCT CCCCGGC.GA AAAAAACAAA

MAR TGTCGCGGGG CACTCCTACT TGG.TGTGCT CCCCGGC.GA AAAAAACAAA

ALB CTTGGCGGGG C..............GTCCT TCCCGGC... CAATAACGAA

CONSENSUS tgtCGCGGGG Cactcctact tgg.tGTgCT CCCCGGC.ga aAAaAACAAA

151

NAN CCCCGGCGCT TACTGCGCCA AGGAACATGA AAA GGAGTG TGCCTGTCCC

TRI CCCCGGCGCT TACTGCGCCA AGGAACATGA AAA.GGAGTG TGCCTGTCCC

LOM CCCCGGCGCT TACTGCGCCA AGGAACATGA AAA.GGAGTG TGCCTGTCCC

COR CCCCGGCGCT TACTGCGCCA AGGAACATGA AAA.GGAGTG TGCCGGTCCC

MCR CCCCGGCGCT TACTGCGCCA AGGAACATGA AAA, GGAGTG TGCCTGTCCC

WEB CCCCGGCGCG GTCTGCGCCA AGGAACAAAA AA.TGGATTG TGCCTATT.T

RP2 CCCCGGCGCG GTCTGCGCCA AGGAACAAAA AA. TGGATTG TGCCTATT.T

PR1 CCCCGGCGCG GTCTGCGCCA AGGAACAAAA AAATGGATTG TGCCTATT.T

VU1 CCACGGCGCT TACTGCGCCA AGGAACATGA AAA.GGAGTG TGCCTGTCCT

vU2 CCACGGCGCT TACTGCGCCA AGGAACATGA AAA.GGAGTG TGCCTGTCCT

ADA CCACGGCGCT TACTGCGCCA AGGAACATGA AAA.GGAGTG TGCCTGTCCT

MCC CCACGGCGCT TACTGCGCCA AGGAACATGA AAA.GGAGTG TGCCTGTCCT

MAR CCACGGCGCT TACTGCGCCA AGGAACATGA AAA.GGAGTG TGCCTGTCCT

ALB CCCCGGCGCG GTCTGCGCCA AGGAACATGA ATACAAGTGT GCCCC. TCCG

CONSENSUS CCCCGGCGCt taCTGCGCCA AGGAACAtgA Aaa.ggagtg tgCCtgTCCt

201

NAN GTGCATCGGT TGGCCGGTGT GGGGACGTGG CACCCAGTAT TAAGAGAT

TRI GTGCATCGGT TTGCCGGTGT GGGGACGTGG CACCCAGTAT TAAGAGAT

LOM GTGCATCGGT TTGCCGGTGT GGGGACGTGG CACCCATTAT TAAGAGAT

COR GTGCATCGGT TTGCCGGTGT GGGGACGTGG CACCCATTAT TAAGAGAT

MCR GTGCATCGGT TTGCCGGTGT GGGGACGTGG CACCCAGTAT TAAGAGAT

WEB GTGC. TCGGT TTACCGAAGC AGGGATGTGG CACTCGATAT TA.TATAT

RP2 GTGC.TCGGT TTACCGAAGC AGGGATGTGG CACTCGATAT TA.TATAT

PR1 GTGC.TCGGT TTACCGAAGC AGGGATGTGG CACTCGGTAT TA.TATAT

vU1 ATGCATCGGT TTGCCGGTGC GGGGATGTGG CACCCAGTAT TAAGAGAT

VU2 ATGCATCGGT TTGCCGGTGC GGGGATGTGG CACCCAGTAT TAAGAGAT

ADA ATGCATCGGT TTGCCGGTGC GGGGATGTGG CACCCAGTAT TAAGAGAT

MCC GTGCATCGGT TTGCCGGTGC GGGGATGTGG CACCCAGTAT TAAGAGAT

MAR ATGCATCGGT TTGCCGGTGC GGGGATGTGG CACCCAGTAT TAAGAGAT

ALB CAG..TCGGT TCGCCGGCCG TGGAA.GTGG CACCAAGTCG TA.TATAA

CONSENSUS gtGcaTCGGT TtgCCGgtgc gGGgAtGTGG CACCCagTat TAagAgAt

Fig. 2 Aligned DNA sequences of the ITS1 region of the $18 \mathrm{~S}-5.8 \mathrm{~S}-26 \mathrm{~S}$ nuclear ribosomal DNA from 13 beet accessions in the genus Beta and an outgroup species (Chenopodium album). Accessions abbreviations are indicated on the left and the gap positions are indicated as dots. 
and total genomic DNA (Jung et al., 1993) and the distribution of satellite DNA families (Schmidt et al., 1991; Schmidt \& Heslop-Harrison, 1993). There is also general agreement with the classifications produced by Santoni \& Berville (1992) using variation in four restriction enzyme sites in the IGS region of rDNA in nine Beta species; no differences in restriction sites for the enzymes EcoRI, $B a m \mathrm{HI}$, HindIII or SacI were found in the ITS1 region of these species, and this is in agreement with our data.

A number of key points emerge from our results with respect to Beta taxonomy and phylogeny. For example, it is clear from both ITS1 sequence data and RAPD banding profiles that there is a considerable divergence of section Procumbentes from the other three sections; this agrees with results from other molecular studies (Kishima et al., 1987; Mita et al., 1991; Santoni \& Berville, 1992; Senda et al., 1995). With regard to section Nanae, represented by the single species $B$. nana, the RAPD banding patterns suggest a lack of genetic variation within this species and that it is closely related to species of section Corollinae. This relationship has also been demonstrated in studies using RFLPs of minisatellite DNA (Jung et al., 1993) and hybridization of satellite DNA family probes cloned from species $B$. corolliflora and B. trigyna (Schmidt \& HeslopHarrison, 1993). In the studies of Jung et al. (1993), Nanae was grouped within section Corollinae, which is also the case for our ITS1 results, whereas our RAPD data and the study by Schmidt \& HeslopHarrison (1993) showed Nanae to be separated from, but closely allied to, section Corollinae. In either case, the conclusion must be that sections Nanae and Corollinae are closely related phylogenetically.

Section Procumbentes includes three species, $B$. patellaris, B. procumbens and B. webbiana. Beta patel-
Fig. 3 Phylogenetic tree based upon data using the neighbour-joining method with the Kimura two-parameter distances displayed.

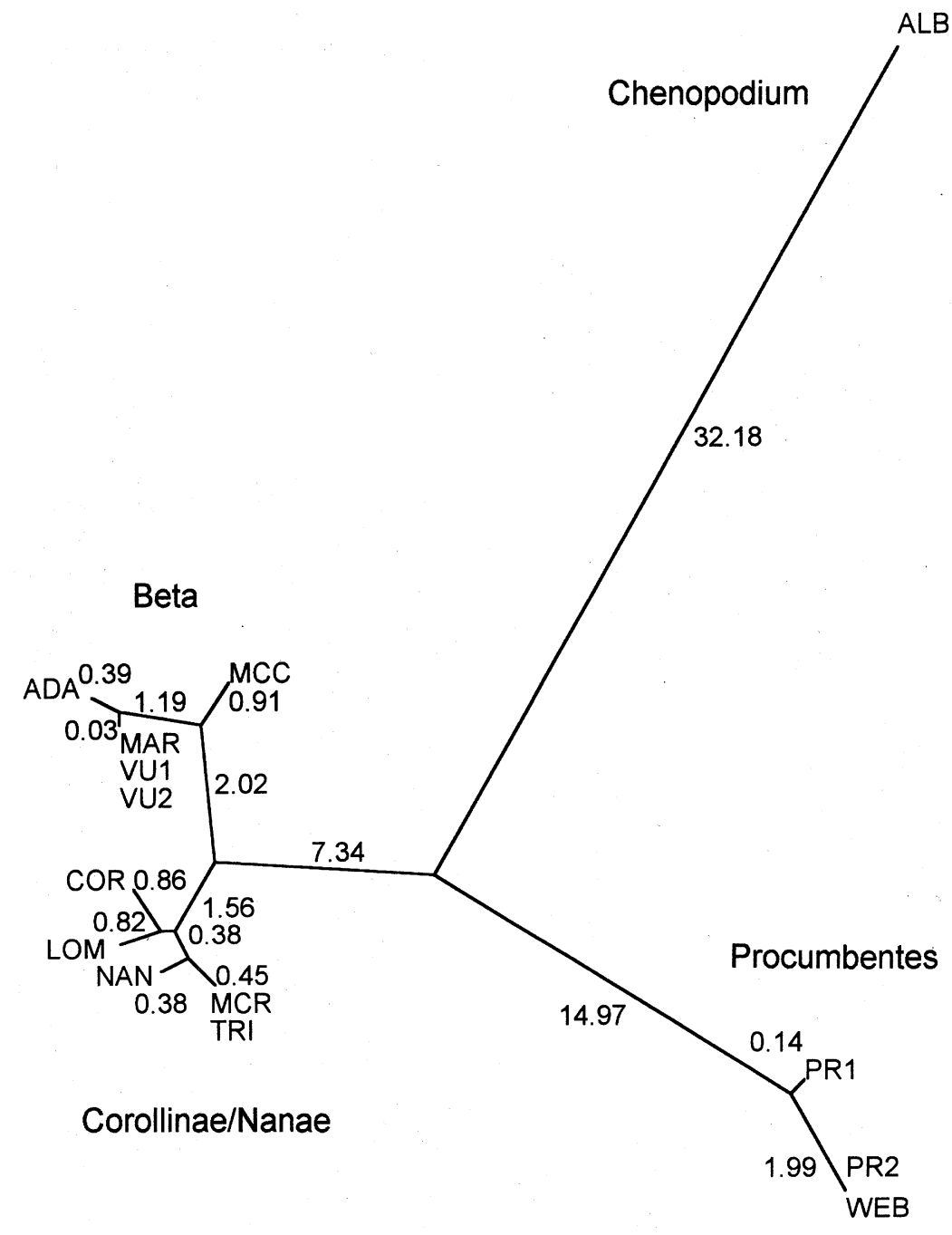

(C) The Genetical Society of Great Britain, Heredity, 80, 624-632. 

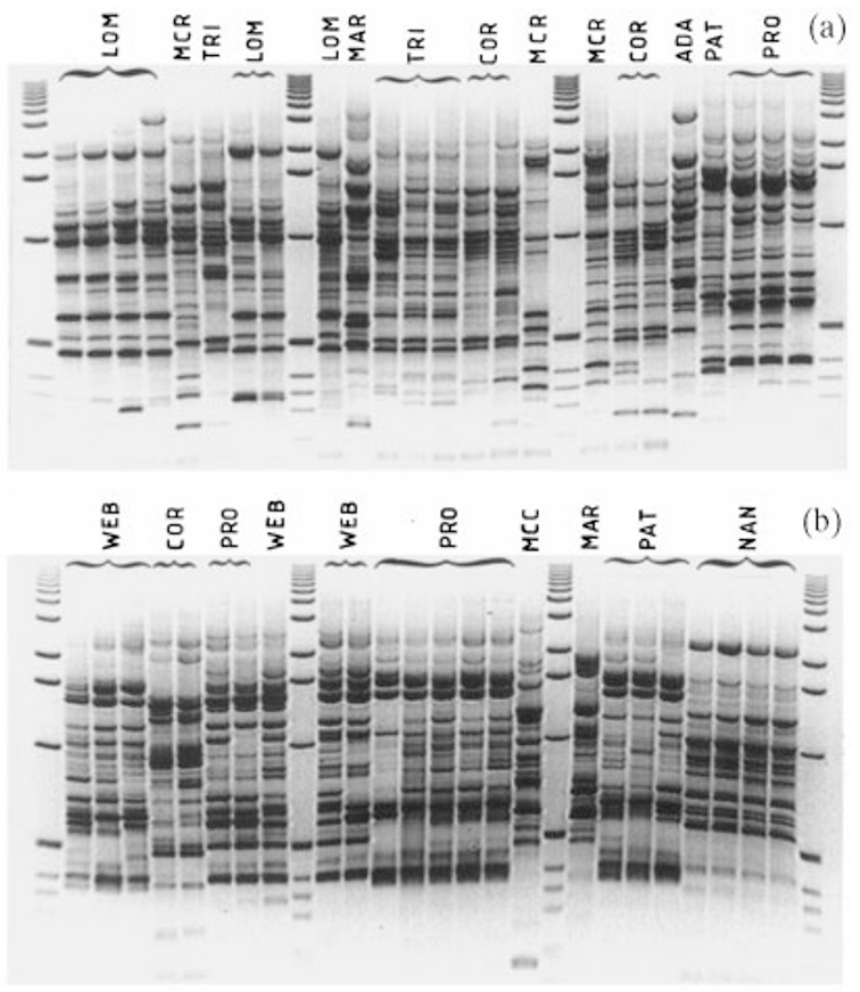

laris has been regarded as an allotetraploid (Abe et al., 1987; Senda et al., 1995), with B. procumbens and $B$. webbiana as diploids. Molecular studies have recently suggested that the last two are extreme forms of the same species (Wagner et al., 1989; Mita et al., 1991; Jung et al., 1993; Kishima et al., 1995), a situation originally proposed by Curtis (1968) based on morphological characteristics. Our ITS1 sequence data suggest that one accession (B0535), designated by the original collector as $B$. procumbens, may actually be $B$. webbiana. The RAPD results show that considerable variation exists within this section. The subgroupings do not correlate with the original classification into species, which might result from natural gene exchange and could support the singlespecies hypothesis, and an autopolyploid origin for B. patellaris (Santoni \& Berville, 1992). Section Procumbentes is, however, the most genetically distinct of all sections within the genus, and this is supported by both RAPD and sequence data. Phylogenetic analysis of the sequence data, with $C$. album included as an outgroup to root the tree, indicates that section Procumbentes diverged from the other forms of beet at a relatively early stage in the evolution of the genus, a conclusion that is also supported by Santoni \& Berville (1992).

As for section Corollinae, accessions of B. lomatogona formed a distinctive group using RAPD data,

\begin{abstract}
Fig. 4 RAPD profiles showing variation in band patterns between samples. The amplification was carried out using primer OPM17. M indicates molecular size markers. Lanes 1-24 (from left to right): (a) B0205-1, B0205-2, B0213-1, B0213-2, B0221-3, B0224-2, B0234-1, B0234-2, B0234-3, B0317, B0349-1, B0367-1, B0367-3, B0368-1, B0368-2, B0397-1, B0397-2, B0403-1, B0403-2, B0424, B0534-1, B0535-1, B0535-2 and B0535-3; (b) B0536-1, B0536-2, B0536-3, B0537-1, B537-2, B0555-1, B0555-2, B0566-1, B0566-2, B0566-3, B0576-1, B0576-2, B0576-3, B0576-4, B0576-5, B0588, B0731, B1108-1, B1108-2, B1108-3, FD19-1, FD24-1, FD24-2, FD25-1 (numbers after the hyphens are plant numbers within accessions). Species are identified using the abbreviations included in Table 1.
\end{abstract}

but much variation was observed in the group composed of the other three species. This may, in part, result from difficulty with taxonomic identification within this section. It seems just as likely, however, that it is because B. macrorhiza, B. corolliflora and $B$. trigyna are closely related phylogenetically. Reamon-Buttner et al. (1996) indicated that these three species are distinct from $B$. lomatogona and that $B$. macrorhiza is ancestral to both $B$. corolliflora and $B$. trigyna, which have evolved through various hybridizations. If this is the case, then one might expect a lack of discrimination between these species in our RAPD analysis. Santoni \& Berville (1992) also separated B. lomatogona from B. macrorhiza, $B$. trigyna and $B$. corolliflora using variation in restriction sites within the IGS region of rDNA.

The sequence data provide direct information about mutations in DNA that accompany divergence of species. In further work, we have developed protocols that exploit these ITS1 sequence differences to define specific primers, which allow the identification of Beta taxa using single locus PCR (data not shown). However, in the context of genetic relationships, it is important to remember that the sequence data reflect variation at only a single locus (ITS1), whereas the RAPD analysis used data from 31 loci. A potential problem with the RAPD data is some co-migrating bands, which may not be allelic. 
Fig. 5 Dendrogram of genetic similarity (Jaccard's) and the UPGMA cluster method using the 48 wild beet samples and 31 RAPD markers. Numbers after the hyphens are individual plant numbers; species abbreviations are also included.

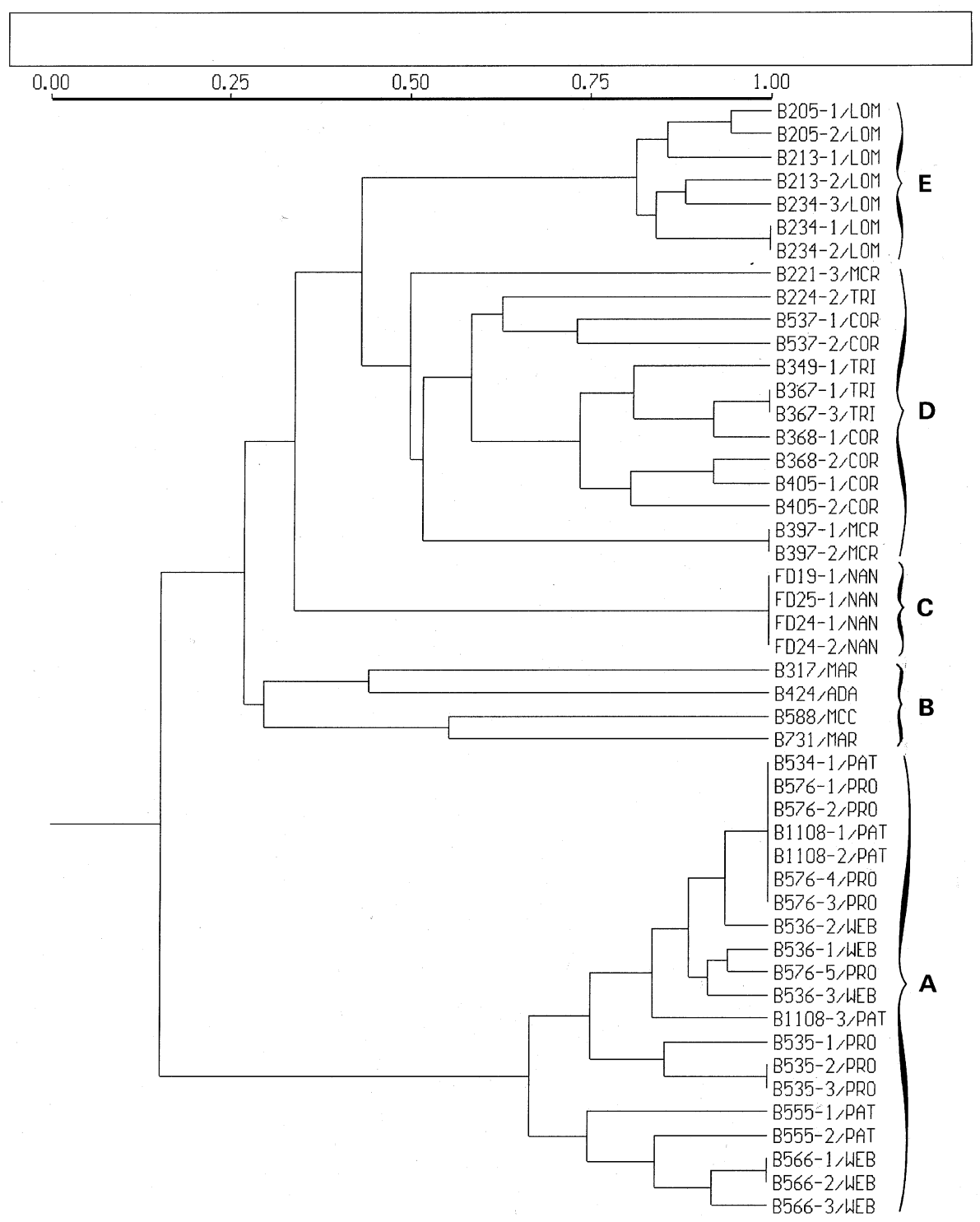

The results obtained here indicate that the patterns of interspecific relationships revealed by the RAPD data are broadly similar to those revealed using sequence data, although there are some differences. For instance, the plants of $B$. macrorhiza and $B$. trigyna possessed identical ITS1 sequences and were closely linked to B. nana; however, all three were clearly separated using RAPD data. This suggests that the RAPD data may provide a more accurate picture of relationships at the species level. This is supported by the concordance of these results with those of Reamon-Buttner et al. (1996) even to the extent that two forms of $B$. macrorhiza may exist; the two accessions used here appear to be very distinct. Overall, the results demonstrate the value of using more than one molecular technique for the analysis of genetic relationships.

\section{References}

ABE, J., NAKASHIMA, H. AND TSUDA, C. 1987. Isozyme variation and species relationships in the genus Beta. Mem. Fac. Agr. Hokkaido Univ., 15.

BALDWIN, B. G. 1992. Phylogenetic utility of the internal transcribed spacer of nuclear ribosomal DNA in plants: an example from Compositae. Mol. Phylogenet. Evol., 1, 3-16.

BALDWIN, B. G. 1994. Molecular phylogenetics of Calycadenia (Compositae) based on ITS sequences of nuclear ribosomal DNA: chromosomal and morphological evolution re-examined. Am. J. Bot., 81, 254. 
BRUMMER, E. C., BOUTON, J. H. AND KOCHERT, G. 1995. Analysis of annual Medicago species using RAPD markers. Genome, 38, 362-367.

CURTIS, G. J. 1968. Observations of fruit shape and other characters in the species of the section Patellares, genus Beta. Euphytica, 17, 485-491.

DEMEKE, T. AND ADAMS, R. P. 1994. The use of PCR-RAPD analysis in plant taxonomy and evolution. In: Griffin, H. G. and Griffin, A. M. (eds) PCR Technology: Current Innovations, pp. 179-191. CRC Press, Boca Raton, FL.

GCG. 1995. GCG Program Manual Version 8.1 (VMS), Vol. 2. Genetics Computer Group Inc., Madison, WI.

JUNG, C., PILLEN, K., FRESE, L., FAHR, S. AND MELCHINGER, A. E. 1993. Phylogenetic relationships between cultivated and wild species in the genus Beta revealed by DNA 'fingerprinting'. Theor. Appl. Genet., 86, 449-457.

KISHIMA, Y., MIKAMI, T., HIRAI, A., SUGIURA, M. AND KINOSHITA, T. 1987. Beta chloroplast genomes: analysis of fraction I protein and chloroplast DNA variation. Theor. Appl. Genet., 73, 330-336.

KISHIMA, Y., YANAI, Y., KINOSHITA, T. AND MIKAMI, T. 1995. Physical mapping of differences between the chloroplast DNAs of Beta vulgaris and B. webbiana. Plant Breed., 114, 361-362.

MARTIN, C., JULIANO, A., NEWBURY, H. J., LU, B.-R., JACKSON, M. T. AND FORD-LLOYD, B. V. 1997. The use of RAPD markers to facilitate the identification of Oryza species within a germplasm collection. Genet. Res. Crop Evol., 44, 175-183.

MILlAN, T., OSUNA, F., COBOS, s. AND TORRES, A. M. 1996. Using RAPDs to study phylogenetic relationships in Rosa. Theor. Appl. Genet., 92, 273-277.

MITA, G., DANI, M., CASCIARI, P., PASQUALI, A., SElVA, E., MINGANTI, C. AND PICCARDI, P. 1991. Assessment of the degree of genetic variation in beet based on RFLP analysis and the taxonomy of Beta. Euphytica, 55, 1-6.

OLMSTEAD, R. G. AND PALMER, J. D. 1994. Chloroplast DNA systematics: a review of methods and data analysis. Am. J. Bot., 81, 1205-1224.

REAMON-BUTTNER, S. M., WRICKE, G. AND FRESE, L. 1996. Interspecific relationship and genetic diversity in wild beets in section Corollinae genus Beta: isozyme and RAPD analyses. Genet. Res. Crop Evol., 43, 261-274.

ROHLF, F. J. 1992. NTSYS-pc, Numerical Taxonomy and Multivariate Analysis System. Exeter Software, New York.

SABIR, A., NEWBURY, H. J., TODD, G., CATTY, J. P. AND FORDLLOYD, B. V. 1992. Determination of genetic stability using isozymes and RFLPs in beet plants regenerated in vitro. Theor. Appl. Genet., 84, 113-117.
SAMBROOK, K., FRITSCH, J. F. AND MANIATIS, T. 1989. Molecular Cloning: a Laboratory Manual. Cold Spring Harbor Laboratory Press, Cold Spring Harbor, NY.

SANTONI, S. AND BERVILle, A. 1992. Characterisation of the nuclear ribosomal DNA units and phylogeny of Beta L. wild forms and cultivated beets. Theor. Appl. Genet., 83, 533-542.

SCHMIDT, T. AND HESLOP-HARRISON, J. S. 1993. Variability and evolution of highly repeated DNA sequences in the genus Beta. Genome, 36, 1074-1079.

SCHMIDT, T., JUNG, C. AND METZLAFF, M. 1991. Distribution and evolution of two satellite DNAs in the genus Beta. Theor. Appl. Genet., 82, 793-799.

SCHMIDT, T., SCHWARZACHER, T. AND HESLOP-HARRISON, J. S. 1994. Physical mapping of rRNA genes by fluorescent in-situ hybridization and structural analysis of $5 \mathrm{~S}$ rRNA genes and intergenic spacer sequences in sugar beet (Beta vulgaris). Theor. Appl. Genet., 88, 629-636.

SENDA, M., ONODERA, Y., KINOSHITA, T. AND MIKAMI, T. 1995. Mitochondrial gene variation and phylogenetic relationships in the genus Beta. Theor. Appl. Genet., 90, 914-919.

SHEN, Y., NEWBURY, H. J. AND FORD-LLOYD, B. V. 1996. The taxonomic characterisation of annual Beta germplasm in a genetic resources collection using molecular markers. Euphytica, 91, 205-212.

SWOFFORD, D. L. AND OLSEN, G. J. 1990. Phylogeny reconstruction, In: Hillis, D. M. and Moritz, C. (eds) Molecular Systematics, pp. 411-501. Sinauer Associates, Sunderland, MA.

VIRK, P. S., FORD-LLOYD, B. V., JACKSON, M. T. AND NEWBURY, H. J. 1995. Use of RAPD for the study of diversity within plant germplasm collections. Heredity, 74, 170-179.

WAGNER, H., GIMBEL, E. M. AND Wricke, G. 1989. Are Beta procumbens Chr. Sm. and Beta webbiana Moq. different species? Plant Breed., 102, 17-21.

WHITE, T. J., BRUNS, T., LEE, S. AND TAYLOR, J. 1990. Amplification and direct sequencing of fungal ribosomal RNA genes for phylogenetics. In: Innes, M., Gelfand, D., Sninsky, J. and White, T. (eds) PCR Protocols: a Guide to Methods and Applications, pp. 315-322. Academic Press, San Diego, CA.

WILliAMS, J. G. K., KUBILEK, A. R., LIVAK, K. J., RAFALSKI, J. A. AND TINGEY, s. 1990. DNA polymorphisms amplified by arbitrary primers are useful as genetic markers. Nucl. Acids Res., 18, 6531-6535.

yokota, Y., KAWATA, т., KATO, A. AND tANIFUJi, s. 1989. Nucleotide sequences of the 5.8S rRNA gene and internal transcribed spacer regions in carrot and broad bean ribosomal DNA. J. Mol. Evol., 29, 294-301. 